\title{
Role of the Renal Nerve in Glucocorticoid Hypertension
}

\author{
Setsuko YOSHIDA, Kenichi YAMADA, Yasushi TAMURA \\ AND SHO YOSHIDA
}

The Second Department of Internal Medicine, School of Medicine, Chiba University, 1-8-1 Inohana, Chiba City, 280 Japan

\begin{abstract}
The present study was designed to investigate the involvement of the renal nerve in glucocorticoid hyp rtension and to assess the role of the renin-angiotensin system in dexamethasone-induced hypertension. The elevated blood pressure in dexamethasone treated rats showing a significant increase in plasma renin concentration (PRC) and activity (PRA) was attenuated dose-dependently by the angiotensin I converting enzyme (ACE) inhibition. Bilateral renal denervation caused a partial decrease in the elevated blood pressure, abolished the increased PRC and PRA, and reduced the dose-dependent decrease in blood pressure with ACE inhibition in dexamethasone treated rats. Although the reduction in body weight and increases in urine volume, urinary sodium excretion and hematocrit were clearly seen following dexamethasone administration, dexamethasone-treated renal denervated rats showed the same degree of change in any of the variables as dexamethasone-treated sham-operated rats. Thus, our results indicate that the stimulation of the renin-angiotensin system through the activation of the renal nerve may be partially responsible for the dexamethasone-induced high blood pressure and, therefore, bilateral renal denervation reduces, partially but significantly, the elevated blood pressure, suggesting that the attenuation of oversecretion of renin contributes to the lowering of the blood pressure.
\end{abstract}

Although the pathogenesis of glucocorticoid-induced hypertension still remains unclear (Dlakos et at., 1978 ; Elijovich and Krakoff, 1980; Krakoff and Bamsel, 1975), the participation of the renin-angiotensin system has been demonstrated (Krakoff et al., 1975; Suzuki et al., 1982). Indeed, Krakoff et al. (1975) offered the strongest

Received August 10, 1988

The name and address to which correspondence should be sent: KENICHI YAMADA, The Second department of Internal Medicine, School of Medicine, Chiba, University, 1-8-1 Inohana, Chiba City, 280 Japan evidence regarding the role of the reninangiotensin system in glucocorticoid hypertension in rats. In their studies, plasma renin activity was increased and the administration of saralasin decreased blood pressure. Recently Suzuki et al. (1982) also demonstrated a renin-angiotensin dependency in glucocorticoid-hypertensive rats, even though they had been maintained on a normal sodium diet.

The release of renin from the kidney has been shown to be largely mediated by three mechanisms, that is, the intrarenal vascular receptor (baroreceptor) which 
senses changes in renal perfusion pressure, the macula densa mechanism and the renal nerves (Davis and Freeman, 1976; Reid et al., 1978). The renal sympathetic nerves can affect control of the renal vasculature and influence renin release (Reid et al., 1978 ; Schrier, 1974; Torretti, 1982). Osborn et al. $(1981,1982)$ have recently demonstrated that very low-level direct stimulation of the renal nerves in dogs increases renin secretion without inducing any change in renal blood flow, glomerular filtration rate, sodium excretion, or renal perfusion pressure.

Thus, although the renal sympathetic activity was strongly involved in renin secretion, the contributory role of the renal nerve to the renin-angiotensin system in hypertension of Cushing's syndrome or glucocorticoid induced hypertension still remains unclear. Indeed, although the importance of the renal nerves has been well documented in DOCA-salt hypertensive rats (Katholi et al., 1980; Katholi et al., 1983), little has been reported as to the role of the renal nerve in the development or maintenance of glucocorticoid-hypertension. Therefore, this study was designed to investigate the involvement of the renal nerve in glucocorticoid-hypertension and to assess the role of the renin-angiotensin system in dexamethasone induced hypertension.

\section{Materials and Methods}

Male Sprague-Dawley (SD) rats (CharlesRiver Laboratory) at 8 weeks of age, weighing $270 \mathrm{~g}$ to $300 \mathrm{~g}$, were used in this experiment. Throughout the study they were housed in a room at constant temperature $\left(24 \pm 1^{\circ} \mathrm{C}\right)$, and humidity $(60 \pm 5 \%)$ and with automatic lighting from $6 \mathrm{a} . \mathrm{m}$. to $6 \mathrm{p} . \mathrm{m}$. To assess the sodium and water handling, the rats were housed individually in metabolic cages. They had free access to distilled water, and were fed ad libitum with a standard chow.

\section{Renal Denervation}

To examine the effect of renal denervation on dexamethasone (DEX) induced hypertension, the male SD rats were subjected 'to bilateral renal denervation (RND) or sham-operation (SHAM) at 8 weeks of age. Under pentobarbital sodium ( $50 \mathrm{mg} / \mathrm{kg}$ i.p.) anesthesia, in RND both kidneys were exposed through flank incision, and the renal nerve and connective tissue were stripped away surgically from the renal artery and swabbed with $95 \%$ ethanol followed by the application of a string soaked in $10 \%$ phenol around the vessel for $10 \mathrm{~min}$. In SHAM both kidneys were exposed in the same way, but nerves, blood vessels, and perirenal tissue were left untouched. Observations were made 4 days after surgery.

The effectiveness of renal denervation was evaluated by measuring norepinephrine content in tissue obtained from kidneys in all RND and SHAM by high performance liquid chromatography. Norepinephrine content in kidneys from RND with DEX untreated and treated averaged $3.92 \pm 0.64 \mathrm{ng} / \mathrm{g}$ tissue $(n=10)$ and $4.42 \pm$ $0.71 \mathrm{ng} / \mathrm{g}$ tissue $(\mathrm{n}=13)$, respectively. Then, these values represented less than $5 \%$ of the norepinephrine content of kidneys obtained from SHAM (SHAM with DEX untreated; $95.03 \pm 11.31 \mathrm{ng} / \mathrm{g}$ tissue $(\mathrm{n}=10)$ and SHAM with DEX treated; $118.52 \pm 14.20 \mathrm{ng} / \mathrm{g}$ tissue $(n=13))$.

\section{Experimental Procedures}

Four days after operation, the RND and SHAM were randomly separated into two Subgroups. Subgroup 1 rats were without DEX administration (vehicle administration) and subgroup 2 rat were treated with DEX.

Rats were anesthetized with scdium pentobarbital $(50 \mathrm{mg} / \mathrm{kg}$ i.p.) and an Alzet osmotic minipump (model 2001, Alza) was placed in the subcutaneous region. The pumps were filled with DEX or vehicle. Assuming that the pumps dispensed fluid at the specified rate of $1.0 \mu 1 / \mathrm{hr}$, the calculated infusion rate of DEX was $75 \mu \mathrm{g} / \mathrm{day}$. Body weight (BW), $24 \mathrm{hr}$ water intake (WI), urine volume (UV), urinary excretion of sodium (UNaV) and creatinine, and hematocrit were determined before and on the 7 th day after implantation of the minipumps. For monitoring blood pressure, the catheter 
was inserted on the 5th day of dexamethasone or vehicle administration. Rats were anesthetized with pentobarbital sodium $(50 \mathrm{mg} / \mathrm{kg}$ i.p. $)$ and a PE-50 catheter was inserted into the lower abdominal aorta via the right femoral artery. The catheter was secured, tunneled subcutaneously, and exteriorized between the scapulae. The catheter was subsequently filled with sodium heparin $(1000 \mathrm{U} / \mathrm{ml})$. Blood pressure was measured on the 7th day in conscious, freely moving rats with a pressure transducer (Nihonkoden. AP 601 G) coupled to a polygraph (Nihonkoden, WI $621 \mathrm{G}$ ). The pressure documented was the average during the final $20 \mathrm{~min}$ of a $45 \mathrm{~min}$ recording period. Then $0.5 \mathrm{ml}$ of blood was collected from the catheter in order to determine the plasma renin activity (PRA) and concentration (PRC).

In order to assess the role of the endogenouse renin-angiotensin system, angiotensin I converting enzyme inhibitor, captopril, dissolved in $0.9 \%$ solution was injected in doses of 0 (vehicle), 30 or $300 \mu \mathrm{g} / \mathrm{kg}$ at intervals of $60 \mathrm{~min}$.

\section{Analytical Method}

PRA and PRC were measured by radioimmunoassay of angiotensin I generation by the method of Poulsen and Jorgensen (1974). Renal norepinephrine content was measured by high performance liquid chromatography (Anton and Sayre, 1962). The sodium concentration in urine was determined by flame photometry. The Creatinine concentrations in urine and blood were determined by Jaffe's method (Chasson et al., 1961).

\section{Statistical Analysis}

Student's $t$-tests were used to evaluate the statistical significance. All data were reported as the mean $\pm \mathrm{SE}$.

\section{Results}

Fig. 1 shows the changes in blood pressure in RND and SHAM with and without DEX administration. DEX administration in both SHAM and RND produced a significant rise in mean arterial pressure $(121 \pm 3 \mathrm{mmHg}$ versus $87 \pm 4 \mathrm{mmHg}$ in SHAM without DEX administration, $\mathrm{p}<0.01$, and $102 \pm 4 \mathrm{mmHg}$ versus $85 \pm 4$
$\mathrm{mmHg}$ in RND without DEX administration, $p<0.05$, respectively). However, the mean arterial pressure of RND without DEX administration was not significantly different from that of the control. In contrast, with DEX administration, renal denervation resulted in a significant decrease in mean arterial pressure $(p<0.05)$ compared with the sham operation.

There was no significant difference in

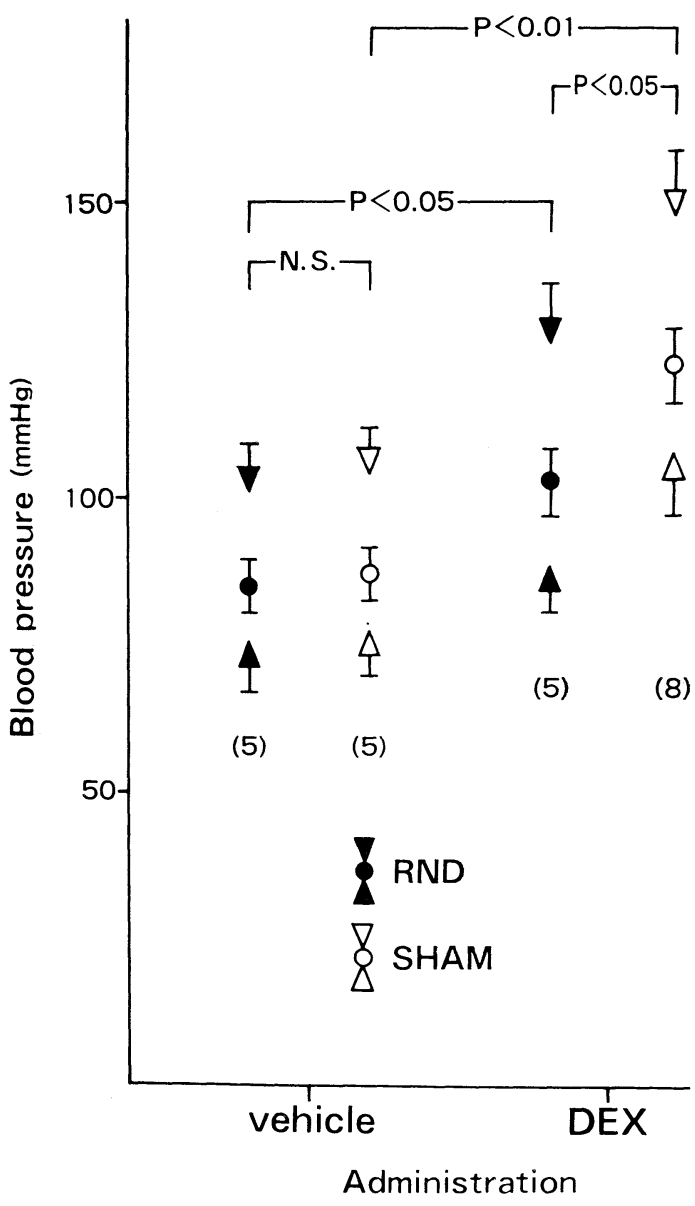

Fig. 1. Blood pressure with or without dexamethasone administration in bilateral denervated (RND) and sham operated rats (SHAM). Statistical significance of mean blood pressure is shown. Numerals in parentheses are numbers of rats. 
Table 1. Plasma renin concentration (PRC) and plasma renin activity (PRA) in renal denervatad (RND) and sham operated (SHAM) rats with or without dexamethasone (DEX) administration

\begin{tabular}{|c|c|c|c|c|}
\hline & \multicolumn{4}{|c|}{ Administration } \\
\hline & \multicolumn{2}{|c|}{ Vehicle } & \multicolumn{2}{|c|}{ DEX } \\
\hline & SHAM & RND & SHAM & RND \\
\hline PRC (ng ANG $\mathrm{I} / \mathrm{ml} / \mathrm{hr}$ ) & $\begin{array}{l}29.4 \pm 2.2 \\
\text { (5) }\end{array}$ & $25.8 \pm \frac{3.9}{(5)}$ & $38.8 \pm 4.2^{(1)}$ & $26.1 \pm 3.1^{(2)}$ \\
\hline PRA (ng ANG I/ml/hr) & $\begin{array}{l}2.0 \pm 0.1 \\
(5)\end{array}$ & $\begin{array}{c}1.8 \pm 0.3 \\
(5)\end{array}$ & $\begin{array}{c}2.5 \pm 0.2^{(1} \\
(8)\end{array}$ & $\frac{1.7 \pm 0.3^{(2}}{(5)}$ \\
\hline
\end{tabular}

(1: $\mathrm{p}<0.05$, as compared to SHAM with vehicle.

(2: $\mathrm{p}<0.05$, as compared to SHAM with DEX.

Numerals in parentheses are numbers of rats.

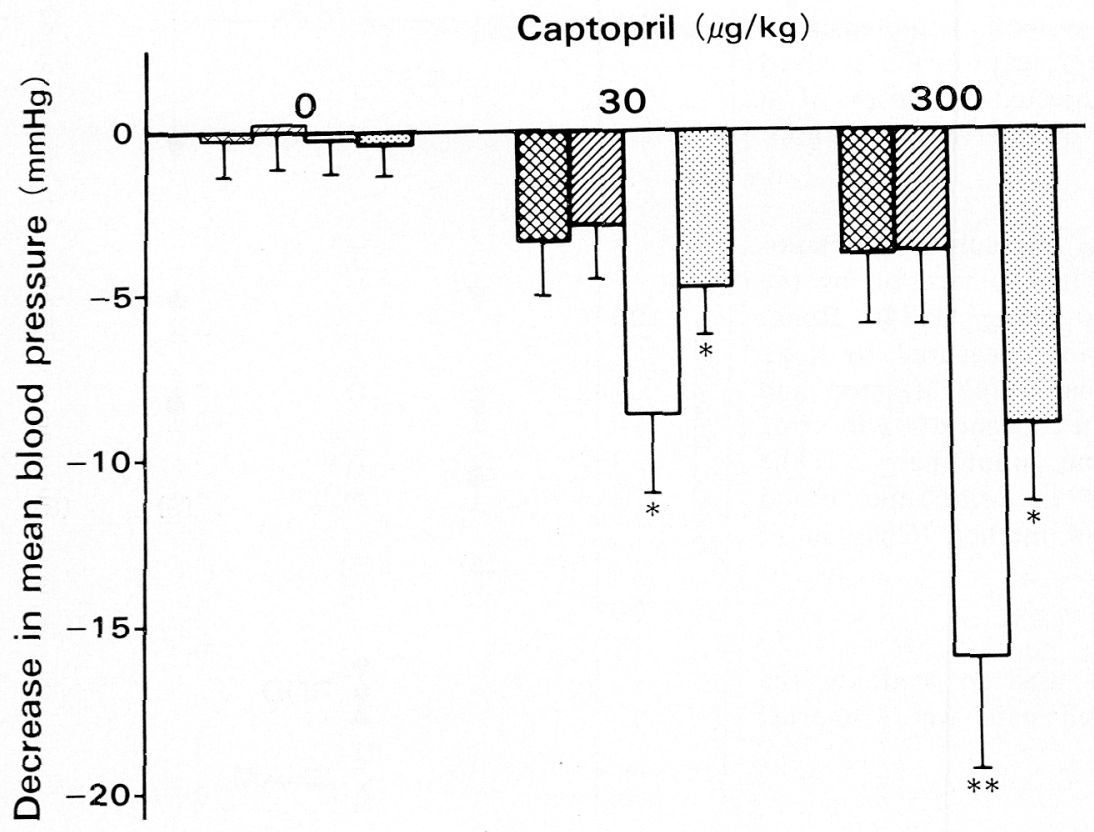

Fig. 2. Decrease in mean blood pressure after injection of angiotensin I converting enzyme inhibitor, captopril, in doses of 0 (vehicle), 30 or 300 $\mu \mathrm{g} / \mathrm{kg}$. Decrease in mean blood pressure due to captopril in RND with DEX administration was significantly less than that in SHAM with DEX administration at each dose of captopril $(\mathrm{p}<0.05)$.

: SHAM with vehicle administration (number of rats; $n=5$ ),

पया? RND with vehicle administration $(n=5)$,

$\square$ : SHAM with DEX administration $(n=5)$,

ㄱ. RND with DEX administration $(n=5)$.

$* \mathrm{p}<0.05$, and $* * \mathrm{p}<0.01$, as compared with control value. 
PRC or PRA of RND without DEX administration compared to SHAM (Table 1). Although DEX administration significantly increased PRC and PRA of SHAM, RND significantly abolished the increases (Table 1).

When angiotensin I converting enzyme inhibitior, captopril, was administered, mean blood pressure significantly and dosedependently decreased in SHAM treated with dexamethasone (Fig, 2). On the other hand, in vehicle administered rats, whether they were sham operated or renal denervated, captopril caused no significant decrease in blood pressure. On the other hand, RND significantly attenuated the decrease in mean blood pressure due to captopril in rats treated with DEX $(p<$ 0.05 , as compared with SHAM with DEX administration, Fig. 2).

Administration of dexamethasone caused a marked reduction in body weight and significant increases in urine volume, urinary sodium excretion and hematocrit in both RND and SHAM, showing similar changes in all of the variable in both (Table 2).

\section{Discussion}

Although the exact mechanism of glucocorticoid hypertension still remains unkown a renin-angiotensin dependency has been suggested by several investigators (Krakoff et al., 1975 ; Suzuki et al., 1982). In our experiments, evidence that the plasma renin concentration and activity were increased and a dose-dependent decrease in blood pressure with angiotensin I converting enzyme inhibition was observed in these dexamethasone induced hypertensive rats, indicates renin-angiotensin dependency. The dose-dependent decrease in blood pressure with angiotensin I converting enzyme inhibition in glucocorticoidhypertensive rats has already been reported

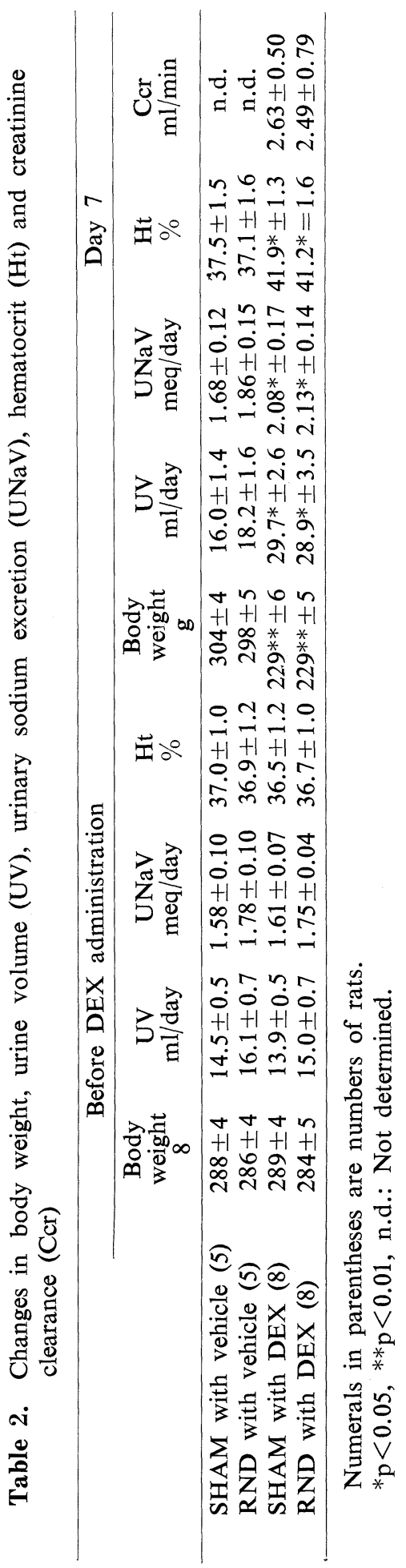


(Suzuki et al., 1982). Although angiotensin I converting enzyme inhibitor, captopril, actually inhibits kininase II as well as angiotensin I converting enzyme and, therefore, the activation of the kallikreinkinin system might be involved in the decrease in blood pressure with captopril administration, glucocorticoids were reported to suppress the kallikrein-kinin system (Bönner et al,, 1981 ; Saruta et al., 1986) and, in addition, the decrease in blood pressure induced by captopril administration was observed only when dexamethasone was administered. Therefore, the possibility of the involvement of the kallikrein-kinin system in the decrease in blood pressure with angiotensin I converting enzyme inhibition in dexamethasone treated rats might be relatively low. In the present study, it is a very important and new finding that bilateral renal denervation caused a partial decrease in its elevated blood pressure, abolished the increased plasma renin concentration and activity, and also reduced the dose-dependent decrease in blood pressure with angiotensin I converting enzyme inhibition in dexamethasone treated rats. These results suggest that the renal nerve plays an important role in the development or maintenance of high blood pressure due to dexamethasone administration in rats, that is, the activation of the renin-angiotensin system with dexamethasone treatment was actually affected by renal nerve activity.

It is well known that an excess amount of glucocorticoid causes sodium depletion in rat (De Bermudez and Hayslett, 1972; Popovtzer et al., 1973). In our experiment too, dexamethasone treatment resulted in almost doubling of the urine volume, significant increases in urinary sodium excretion and hematocrit, and a marked decrease in body weight, indicating that treatment with an excess amount of dexamethasone caused volume depletion in these rats. The volume depletion should facilitate the activation of the renin-angiotensin system and the sympathetic nerve system through the baroreflex (Aisenbrey et al., 1981; Andrews and Brenner, 1981 ; Burnier et al., 1983). Thus, the increased plasma renin concentration observed in the dexamethasone treated intact rats may be, in part, responsible for the volume depletion produced by this agent. However, no significant differences were observed in any of the variables, including creatinine clearance, in the renal denervated and the sham operated rats. So it was considered that, at least, the degree of volume depletion due to dexamethasone treatment was almost the same, whether the rats were renal denervated or intact. Therefore, it is likely that the abolishment of the increased plasma renin concentration, found in renal denervated rats, was due to renal denervation itself.

It is not clear to what extent dexamethasone itself increased renal sympathetic nerve activity. However, it is known that glucocorticoid administration induces tryrosine hydroxylase, the initial-step enzyme of neurotransmitter synthesis, in sympathetic ganglia (Hanbauer et al., 1976). This suggests that the action of the transmitter depends on the presence of glucocorticoids, and that these hormones may, in fact, play a fundamental role in neuron transmission. In addition, it was reported that glucocorticoids and other steroids changed the extra-neuronal uptake or metabolism of norepinephrine (Kalsner, 1969 ; Iversen and Salt, 1970). These findings may support the concept that glucocorticoids potentiate or stimulate the overall renal sympathetic nerve activity. Accordingly, it is most likely that the bilateral renal denervation abolished the renal renin response to an excess amount of dexamethasone.

Thus our results indicate that the stimulation of the renin-angiotensin system through the activation of the renal nerve may be partially responsible for the dexamethasone induced high blood pressure 
and, therefore, bilateral renal denervation reduces, only partially but significantly, the elevated blood pressure, suggesting that the attenuation of oversecretion of renin contributes to the lowering of the blood pressure.

\section{References}

Aisenbrey, G. A., W. A. Handelman, P. Arnold, M. Manning and R. W. Schrier (1981). Vascular effects of arginine vasopressin during fluid deprivation in the rat. J. Clin. Invest. 67, 961-968.

Andrews, C. E., Jr. and B. M. Brenner (1981). Relative contribution of arginine vasopression and angiotensin II to maintenance of systemic arterial pressure in the anesthetized waterdeprived rat. Circ. Res. 48, 254-258.

Anton, A. H. and D. F. Sayre (1962). A study of the factors affecting the aluminium oxidetrihydroxyindole procedure for the analysis of catecholamines. J. Pharmacol. Exp. Ther. 138, 360-375.

Bönner, G., R. Antenrieth, M. Marin-Grez, W. Rascher and F. Gross (1981). Effects of sodium loading, deoxycorticosterone acetate, and corticosterone on urinary kallikrein excretion. Horm. Res. 14, 87.

Burnier, M., J. Biollaz, D. B. Brunner and H. R. Brunner (1983). Blood pressure maintenance in awake dehydrated rats: renin vasopressin, and sympathetic activity. Am. $J$. Physiol. 245, H203-H209.

Chasson, A. L., H. J. Grady and M. A. Stanley (1961). Determination of creatinine by means of automatic chemical analysis. Am. J. Clin. Pathol. 35, 83-88.

Davis, J. O. and R. H. Freeman (1976). Mechanisms regulating renin release. Physiol. Rev. 56, 1-56.

De Bermudez, L. and J. P. Hayslett (1972). Effect of methyl-prednisolone on renal function and zonal distribution of blood flow in the rat. Circulation Res. 31, 44-52.

Dlakos, T. G., A. N. Elias and G. H. Anderson (1978). Evidence for an angiotensinogenic mechanism of the hypertension of Cushing's syndrome. J. Clin. Endo. Meta. 46, 114-118.

Elijovich, F. and L. R. Krakoff (1980). Effect of converting enzyme inhibition on glucocorticoid hypertension in rats. Am. J. Physiol.
$238, \mathrm{H}-844-848$.

Hanbauer, I., A. Guidotti and E. Costa (1976). Dexamethasone induces tyrosine hydroxylase in sympathetic ganglia but not in adrenal medulla. Brain Res. 85, 527-531.

Iversen, L. L. and P. T. Salt (1970). Inhibition of catecholamine utake by steroid in the isolated rat heart. Brit. J. Pharm. 40, 528530.

Kalsner. S. (1969). Mechanism of hydrocortisone potentiation of response to epinephrine and norepinephrine in rabbit aorta. Circ. Res. 24, 383-395.

Katholi, R. E., A. J. Naftilan and S. Oparil (1980). Importance of renal sympathetic tone in the development of DOCA-salt hypertension in the rat. Hypertension 2, 266-273.

Katholi, R. C., A. J. Naftilan, S. Bishop and S. Oparil (1983). Role of the renal nerves in the maintenance of DOCA-salt hypertension in the rat. Hypertension 5, 427-435.

Krakoff, L. R., R. Selvadurai and E. Sutter (1975). Effect of methyl-predonisolone upon arterial pressure and renin-angiotensin system in rats. Am. J. Physiol. 228, 613-617.

Krakoff, L. R. and G. N. Bamsel (1975). Pathogenesis of hypertension in Cushing's Syndrome. Am. J. Med. 58, 216-220.

Osborn, J. L., G. F. Dibona and M. D. Thames (1981). Beta-1 receptor mediation of renin secretion elicited by low frequency renal nerve stimulation. J. Pharmacol. Exp. Ther. 216, 265-269.

Osborn, J. L., G. F. Dibona and M. D. Thames (1982). Role of renal $\alpha$-adrenoceptors mediating renin secretion. Am. J. Physiol. 242, F620-626.

Popovtzer, M. M., J. Robinette, C. G. Halgrimson and T. E. Starzl (1973). Acute effect of prednisolone on renal handling of sodium. Am. J. Physiol. 224, 651-658.

Poulsen, K. and J. Jorgensen (1974). An easy radioimmunological microassay of renin activity, concentration and substrate in human and animal plasma and tissues based on angiotensin I trapping by antibody. J. Clin . Endo. Meta. 39, 816-825.

Reid, I. A., B. J. Morris and W. F. Ganong (1978). The renin-angiotensin system. Annu. Rev. Physiol. 40, 377-410.

Saruta, T., H. Suzuki, M. Handa, Y. Igarashi, K. Kondo and S. Senba (1986). Multiple factors contribute to the pathogenesis of hyper- 
tension in Cushing's syndrome. J. Clin. Endocrinol. Metab. 62, 275-279.

Schrier. R. V. (1974). Effect of adrenergic nervous system and catecholamines on renal hemodynamics, sodium, and water excretion and renin secretion. Kidney Int. 6, 291-306. Suzuki, H., M. Handa, K. Kondo and T.
Saruta (1982). Role of renin-angiotensin system in glucocorticoid hypertension in rats. Am. J. Physiol. 243, E48-51.

Torretti, J. (1982). Sympathetic control of renin release. Annu. Bev. Pharmacol. Toxicol. 22, 167-192. 